\section{Politics of climate change}

SIR - I welcome Sonja A. BoehmerChristiansen's recent article ${ }^{1}$ about the politics of climate change, but her presentation is ill-founded.

Boehmer-Christiansen can have no evidence for her assertion that the scientists contributing to the work of the Intergovernmental Panel on Climate Change (IPCC) comprise a narrow group, whose members have advanced the issue of climate change research to raise funds for the support of their own research. Her statement that the IPCC 1990 Science Assessment was produced by Britain, with major assistance from a small group researching ozone science inside the National Aeronautics and Space Administration, is absurd and misleading.

The IPCC process of assessment is open and transparent. It is based on available scientific literature, a peer-review process of the analysis is essential, different views that are scientifically well founded should be described and scientists from both developed and developing countries participate $^{2}$. The basic reports, as well as the summaries for policy-makers, are written by teams of authors from many countries and reviewed by hundreds of scientists.

Boehmer-Christiansen ignores the obvious driving force, that scientists may wish to call attention to findings indicating that continued increase of greenhouse gases in the atmosphere might lead to signficant changes of the climate on Earth. This has generally been done in a careful and well-balanced manner.

Nor is it correct to say that "the global warming has [for IPCC and me as its chairman] become the justification for a crusade against materialism and for a 'new organizing principle' - the preservation of the Earth". This does not address the raison d'etre of the IPCC, to develop a method to provide useful scientific knowledge for the political process.

The IPCC has always emphasized the uncertainty of our knowledge and it is grossly unfair to describe its work as a "skilful exercise in scientific ambiguity". Uncertainty is a reality and it does not diminish risk.

Few, if any, critical remarks about the IPCC conclusions have been published in the peer-reviewed literature by scientists active in the field. But some scientists and lobbying groups with various political agendas have entered the scene. Seldom do these critics rely on widely accepted scientific analyses. BoehmerChristiansen's comments demonstrate a surprising naivety about the complex process of making climate-change policy.

The growing debate about climate change is no surprise. In this context the IPCC has been accused of not being

Panel on Climate Change) objective in its work. Of course no single scientist can be completely objective, particularly about as complex an issue as that of human-induced climate change, but the collective work led by IPCC is generally much more reliable than other attempts to summarize scientific research results for the political process.

\section{Bert Bolin}

(Chairman, Intergovernmental

Kvarnasvägen 6, 18451 Österskär, Sweden

1. Nature 372, 400-402 (1994)

2. Nature 368,94 (1994)

\section{Distorted views}

SIR - Your article on the European Southern Observatory (ESO) (Nature $363,551 ; 1995)$ gives a distorted view of the situation regarding ESO's dealings with the Chilean government.

I did not "pledge" to anything, I did not state any intention to "take the government to international court for breach of contract". Finally, ESO has not entered "a chain of appeals and counter appeals with the Chilean courts" while the "government has stood aside".

There are three issues. The first has to do with guaranteed observing time for Chilean astronomers and guarantees of labour rights for Chilean workers and has been largely resolved through an agreement between the Chilean government and ESO that is awaiting signature and ratification.

The second has to do with the question of the ownership of the land at the time the Chilean government donated it to ESO. Private parties in Chile have claimed ownership at that time. ESO considers this an internal issue for Chile, to be resolved by the Chilean government, and ESO has carefully refrained from entering into this legal controversy.

The third has to do with ESO's immunity of jurisdiction from Chilean courts. This immunity has been clearly recognized by the Chilean government while the other pending issues are resolved. This is important to ESO and to the worldwide astronomical community because stoppage of the work and consequent financial losses would damage the Very Large Telescope project which is in a very advanced stage of completion.

We are confident that through the continued help of the Chilean government an appropriate solution will be found that will permit ESO to continue its work in Chile on behalf of European and worldwide astronomy.

Riccardo Giacconl

European Southern Observatory,

Karl-Schwarzschild-Strasse 2 ,

D-85748 Garching bei München, Germany

\section{The use of Taxol as a trademark}

SIR - I find it, to say the least, ironic that a publication that has adopted the name "Nature" for a magazine about scientific research concerning "nature" should be contending that a trademark of another company is generic (Nature 373, 370; 1995): I must assume that Mother Nature and the trademark examiners were "asleep" when you adopted the name "Nature" for your magazine. The aphorism about people who live in glass houses comes quickly to mind.

Pharmaceuticals are a highly regulated field. Trademarks for pharmaceuticals are subject to review by trademark offices and health authorities around the world. Generic names for pharmaceuticals are also subject to regulation by the World Health Organization (WHO), as well as local authorities such as the United States Adopted Names Council (USAN) and the British Pharmacopeia. After review by numerous authorities in numerous countries, Taxol was approved for our use as a trademark for an anticancer preparation. The generic term approved by WHO, USAN and the British Pharmacopoeia for this product is 'paclitaxel.'

Our Taxol anticancer preparation is sold in more than 40 countries under the trademark Taxol and the trademark is now registered in nearly 70 countries. It is well-known as a trademark of BristolMyers Squibb throughout the oncology community, as is the generic name paclitaxel. The generic name paclitaxel has also become well-recognized in the research community; there are numerous scientific articles using the approved generic name paclitaxel. The fact that some earlier scientific articles used the term 'taxol' as a trivial name has no bearing on whether Taxol is a recognized trademark among oncologists, which it clearly is. To change the brand name of our product, as you suggest, would cause massive confusion and endanger the health and safety of oncology patients. That is a risk we will certainly not take because of a magazine editorial or indeed for any other reason.

I hope for your sake that Mother Nature doesn't wake up and notice your misappropriation of her name. She's been known to have quite a temper.

Stephen Chesnoff

Bristol-Myers Squibb Company,

345 ParkAvenue,

New York, New York 10154-0037, USA

Nature has never prevented anybody from using the word nature as a common noun; the Bristol-Myers Squibb trademark would end a well-established usage. Editor, Nature. 